\title{
A ciência brasileira vai bem. E a tecnologia?
}

Uma percepção notória, que se confirma com os dados sobre ciência e tecnologia (C\&T) no Brasil, é que a ciência vai bem, mas o desenvolvimento tecnológico ainda fica muito a dever ao padrão científico que alcançamos.

De fato, o número de doutores se expandiu admiravelmente desde a década de 90 , assim como o número e a qualidade da nossa pós-graduação, destacando-se a área da saúde. Mesmo os orçamentos globais e mais tradicionais para o fomento à C\&T melhoraram; o Ministério da Saúde entrou de fato no jogo no Governo Lula, destinando e executando um expressivo orçamento para C\&T em saúde, mediante chamadas de editais e programas (http://www.saude.gov.br/sctie/decit/index.htm). As estatísticas da CAPES, do CNPq e FINEP, que contam as boas novidades na ciência brasileira, estão disponíveis e facilmente acessíveis, razão pela qual seria exaustivo e desnecessário repeti-las neste curto espaço.

No caso específico da saúde, tivemos a realização da I Conferência Nacional de Ciência, Tecnologia e Inovação em Saúde, realizada em julho de 2004, em Brasília (relatório no site do Ministério da Saúde). Por sua vez, o Governo Federal lançou, em maio de 2004, a Política Industrial, Tecnológica e de Comércio Exterior (http://www.desenvolvimento. gov.br/arquivo/ascom/apresentacoes/Diretrizes.pdf), a ser implementada por diversos atores do setor público federal (ministérios, BNDES, FINEP e outros), tendo a área de insumos em saúde (fármacos) prioridade em financiamentos, seja para o desenvolvimento industrial, seja para a fomentação de inovações, a serem construídas em parcerias entre instituições de pesquisa e empresas. Para tanto, foi aprovada pelo Congresso Nacional a Lei de Inovação (Lei 10.973, de 02/Dez/2004), que favorece de várias formas essa interação.

Por outro lado, ainda no campo da saúde, a desanimadora realidade quanto à tecnologia também é verdade, seja quando analisamos os chamados insumos em saúde (vacinas, medicamentos, kits e reativos para diagnóstico, equipamentos, material e procedimentos médico-cirúrgicos etc.), seja quando examinamos C\&T nos campos da saúde pública e da clínica.

De fato, no transcorrer de todo o século XX, não tivemos uma única vacina ou fármaco desenvolvidos no Brasil, somente um punhado de recursos para diagnóstico. Nessa área, nossa indústria importa, maquia ou copia. Nossas universidades e institutos pesquisam e ensinam (muitas vezes, muito bem; outras, nem tanto), mas pouco produzem inovações que cheguem de fato aos serviços de saúde.

No campo da saúde pública e da clínica, em que as fronteiras entre conhecimento e aplicação não são muito nítidas, as contribuições também não foram de monta, exceto em alguns momentos da formulação da política de saúde, por exemplo na década de 80 , quando foi construída a proposta do SUS. Mas a academia está longe de fazer chegar sua melhor contribuição aos serviços de saúde também nesses dois grandes campos da pesquisa em saúde.

O que fazer, então? Além de aproveitar elementos do bom momento que vive a ciência brasileira, nas diversas dimensões supracitadas, entendo que as próprias instituições acadêmicas devem buscar de forma ativa uma profunda mudança nas suas relações e inserções com o sistema de saúde. Aqui na FIOCRUZ, por exemplo, criamos dois grandes programas de desenvolvimento tecnológico, um de insumos para a saúde (PDTIS) e outro para os campos da saúde pública e da clínica (PDTSP). Com eles, queremos a instituição como protagonista da formulação e implementação de políticas de saúde, do desenvolvimento de ferramentas para o sistema de saúde, da geração de protocolos assistenciais e gerenciais para o SUS e de inovações em vacinas, medicamentos e recursos diagnósticos. Tudo isso com um fomento dirigido confiável, com qualidade e com avaliação de resultados, para que, tendo como base as melhores evidências científicas, possamos, efetivamente, contribuir para o progresso nas condições de vida e saúde e para a melhoria do nosso sistema de saúde.

Paulo M. Buss

Presidente da Fundação Oswaldo Cruz. 